\title{
Syphilitic aortic aneurysm
}

\author{
Estel E. Surber \\ University of Nebraska Medical Center
}

This manuscript is historical in nature and may not reflect current medical research and practice. Search PubMed for current research.

Follow this and additional works at: https://digitalcommons.unmc.edu/mdtheses

Part of the Medical Education Commons

\section{Recommended Citation}

Surber, Estel E., "Syphilitic aortic aneurysm" (1941). MD Theses. 890.

https://digitalcommons.unmc.edu/mdtheses/890

This Thesis is brought to you for free and open access by the Special Collections at DigitalCommons@UNMC. It has been accepted for inclusion in MD Theses by an authorized administrator of DigitalCommons@UNMC. For more information, please contact digitalcommons@unmc.edu. 
SYPHILITIC AORTIC ANEUPYSM

BY

E. GEORGE SURBER

\author{
SENIOR THESIS PRESFNTED TO \\ UNI VEREITY OF NEBRASKA \\ COLLEGE OF MEDICINE \\ OMAHA, 1941
}




\begin{tabular}{|c|c|}
\hline I NTRODUCTION & $p=g e$ \\
\hline EISTCRY and ETIOLOGY & Eage \\
\hline PATHOLOGY & $\rho \equiv g e$ \\
\hline SYMPTOMATOLOGY & page \\
\hline DIAGNOSIS & page \\
\hline PHYSICAL SICNS & cage \\
\hline TREATMENT-MEDICAL & page \\
\hline TREA TMENT-SURGICAL & $p=g e$ \\
\hline PROGNOSIS & Fage \\
\hline CONCLUSTONS & fage \\
\hline
\end{tabular}




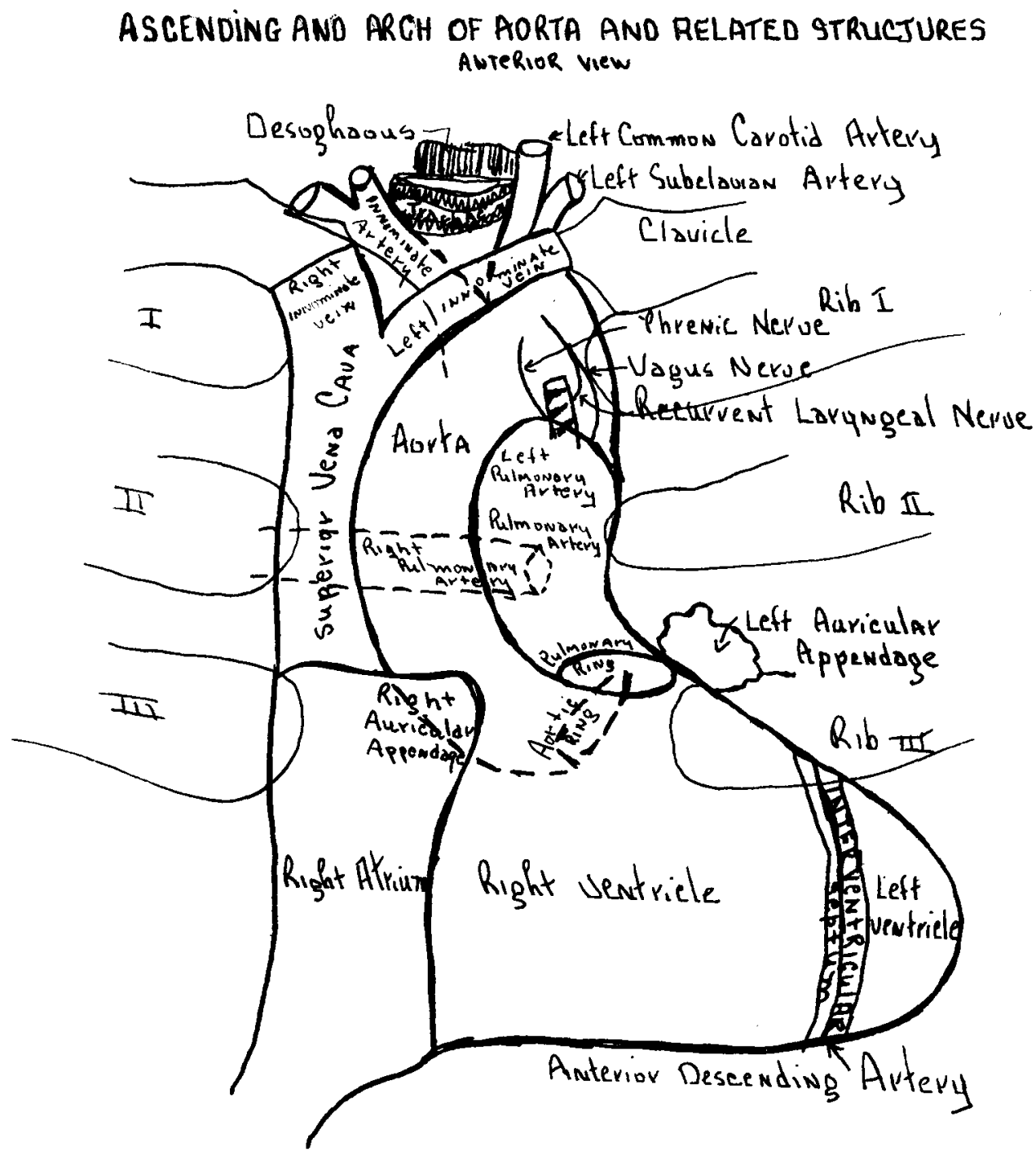

From (55) 


\section{INTRODUCTION}

The Greeks had a mord for Aneurym meanine a widening out or a dilatation of an artery or vein, (18). According to Smith and Gault (73), aneury m may be defined as a cyst-like mass containing blood and communicating with an artery. Two main types are recognized: true aneurysms in which the sac is made up of one or more of the coats of the vesgel wall, and false aneurysms in which the wall is made up by surrounding tissues.

William Boyd (7) says, "A great variety of aneurysms have been quite unnecessarily described". He classifies aneurysm into true and false as above. A fusiform aneurysm is one which is a more or less uniform dilatation of the entire lumen of the vessel throughout an appreciable part of its length. A saccular aneurysm consists of a pouching of the vessel at one point. It may communicate with the vessel by a narrow or wide opening. The arteriovenous aneurysm is an abnormal communication between an artery and vein. Of these there are two types: tranatic and congenitial fistulae. The latter is often called cirsoid aneurysm. It is a direct shunt between an artery and a vein without the interposition of the usual capizzaries and as a result the vein becomes dilated. Any artery may be the site of such a dilatation, but in practice we may distinguish aneurysme of the aorta and its 
main branches, aneurysms of the arteries of the abdominal viscera, the limbs, and of the brain. There are several types of aortic aneuryswi of which we shall discuss the syphilitic aortic aneurys $m$ in this thesis. There are also the rhumatic (usually in children), the rare traumatic form and the dissecting aneurysm.

Shennan (70), who reviewed the literature compiling almost 293 cases of dissecting aneurysms up to 1934 , states that syphilitic etiology is usually regarded as one of the outstanding differences between oyphilitic and dissecting aneurysms. He gives the definition; "A dissecting aneurysm is the lesion produced by penetration of the circulating blood into the substance of the wall of the vessel with subsequent extension of the effused blood for a varying distance between its layers". The etiology is generally believed to be a degeneration of the media, idiopathic and/ or toxic.

Boyd (7) in 1924 reported on 4000 cases of syphilitic aneurysms gathered from the literature. He states that aneurysm 18 not rare; the mortality being $0.1 \%$ to $0.5 \%$ of deaths in American cities.

Wills and Horton (49) in 1938 reported on a large series of aneurysms. Of these $56.9 \%$ were thoracic and of these $85 \%$ were syphilitic, the remaining $15 \%$ being of the dis secting and other types. Most other statis- 
tical studies give slightly higher figures than this, but it is a good avergge of the present trend in incidence of syphilitic aortic aneuryam.

The sex distribution is interesting in that women rarely bave aneurysms. The ratio being on the average I to 10 in favor of the males (25). Other autbors (52) claim that syphilitic aortic aneurysm is twice as common in males than in females. Positive Tasserman reactions can be obtained in $98 \%$ of fatients with aneurysm. of 6,420 patients, $10 \%$ had cardiovascular syphilis; $1 . \%$ of whom had aortic aneuryam. $80 \%$ of 811 patients had never received adequate treatment for early sy hilis. 
In the orient a very ancient knowledge of aneurysm is claired. Acoording to Edmund Owen (cit. (26)), the Hindu surgeon Susruta about 600 B.C. was acquainted with aneurysm, but did not treat it. According to mang, History of Chinese Medicine (81) Aneurysm was known to To'ang Kung, 180 B.C., who, in writing 25 case histories in the Shih Chi Ts'ang Kung Chaun, describes ouch a case. Several syphiloids are described in the anclent literature of India and China (26).

One of the earliest descriptions of rupture of sortic and of abdominal aorta is contained in the work of Aretaeus the Cappadocian, first century A.D. (Cit.t26)). In the light of the modern knowledge, it is clear that Aretaeus in hie deseases of the vena cava has furnished a description of thoracic and abdominal aneurysm of ancient times with unusual clarity.

Galen (18) appears to be the first author in antiquity from whom we learn of aneurysm, and his knowledge was limited to pulsating enlargements occurring underneath the skin. His familiarity chiefly centered about vessels which had been injured and about which a pulsating haematoma had developed which he found could be compressed under the band, causing the disappearance of the mass. By experiment he found that it was unwise to attempt in- 
cision into these tumors without preliminary ligation, for he states that the blood is spouted out with much violence and can scarely be arrested. Furthemore, re observed that when an aneurysm is compressed within the fingers, a peculiar triril is felt within it, caused by the rush of blood. Galen also encountered vascular dilatations in the absence of injury which he concluded to be of the same character as traumatio sneuryem. It is probable that he confused venous dilatatione and arterial aneurysms in his descriptions.

Antyllus, the surgeon (cit. (26)), is supposed to be the first to treet intelligently of aneurysm. He speaks of the dilated and ruptured aneurysms and describes in detail the operation of ligation which has taken his name. This, however, deals with external aneuryoms. Aetilis (1), second century, is the next of the Greeks who came nearer to describing an internal aneurysm. He says the disease may occur in any part of the bcdy, but is most frequently met with in the throat wiere it gives rise to a tumor tha goes by the name of bronchocele.

The Latin surgeons of the midale ages added nothing to what had already been tranmitted from the Greeks. Henry de Mondeville (cit. (26)) gives some intereating comments, particularly on the name. Fe calls attention to the fact that in Avicenna's Cannon it is called by 
$-6-$

"mater sanguinis", a sea or sac of blood; otter nmes being "burismus" and "operisma", frobably through the errors of coypists.

Fernelius (15) in 1542 recognized the difference in the character of the lesion arising from injury, and occurring spontanecualy. He pointed cut that in those cases where an injury had broken a vessel and permitted the escape of blood, the tumorous enlargement was partially cmposed of coagrilum within a oavity and fluid in its center. Furthermore, Fernelius recognized not only the development of aneuryom in the external and superficial vessels but also in the internal arteries, especially in the chest or about the spleen and mesentery where a violent throbbingmay frequently be observed. Ferneliue was the first to bring to our attention the presence of aneurysms in the deep tissues, and, although be did not describe the nature of the aneurysmal dilatation within the thorax, we presume that he was referfing to an aneurysm of the aorta.

The recognition of internal aneurysm during life was first made by Vesalius (cit. (39)) who described its presence in the thorasic and abdominal aorta. Vesalius in 1557 was able to demonstrate the lesion clinically and verify the diagnosis by dissection after death. His findings were very convincing, and he seems to have had 
the opportunity of studying comletely a number of cases.

It was, however, Pare (60) in 1561 who appreciated aneuryam, its severity and mode of origin. To him we owe the first clear description of aneuryam in its different forms. He arplied the term to all types of dilatation of the arteries, whether occasioned by wound or of unknown cause. Pare also recognized the clinical manifeatation of a bruit, which may be perceived either by the ear or by touch when slightly compresoing the tumor. He also observed that thrombosis was very apt to occur within the cavity of the dilated vessel. Pare was very skeftical rescecting the treatment of the larger aneurysm; for the smaller ones he advised ligation. Aneury sms which occur in internal parts be believed were incurable. Pare's belief that aneurysa was so comon in the neck of pregnant women was based on a mistaken diagnogis, in which the vascular enlargement of the thyrold with itg evident pulation was the misleading feature.

It would appear thet in the daya contemporary with Pare, some of the aneurysm desoribed were venous varices. These observations were for the most part made clinically, some of them being dealt with by ourgical means. A clear differentiation betweer fathological process arising upon the erterial and venous channels of the extermities was not made. This confusion is 


\section{$-8-$}

suggeated by the frequency with which the aneurysms were observed upon the extremities.

Even after Pare's description of aneurysm, there sfpeared to be sone confusion as to the actual nature of the tumor. Sennertus (cit. (39) in 1628 again drew attention to the differentiation between subcutaneous and interstitisl blood effusions and aneurysr. He attempted an explanation for the mode of origin of aneuryst and indicated an arpreciation of the structure of arteries.

Te are hardy correct in attempting to associate the aneurysm of these men with any specific disesse, when the fact is bourne in upon that ayphilis was sn unknown disease at that time (39). It is probable, and the reports of Galen (18) bear out, that the aneurysma recorded in his time were traumatic in origin or were associated with forms of arterial disease other than syphilis. The information regarding aneury ms prior: to the close of the fifteenth century is very meager. That aneury was known and oocasionally encountered there is no doubt, but its frequency appears to have been small and its imfortance was inguficient to lead to nuch comment. The aneury ams of the first fifteen centuries of the Christian era appear to have been mainly those attached to the feripheral vessels, and no comment is nade respecting those important tumorous mases of the thorax which are of 
greateat interest today.

Alnogt sudienly with the beginning of the sixteenth century, aneuryams received new prowinence. In part we nay ancribe the greater interest to the more acute observations of the new medicine beginning with these times. However, the history of aneuryam, because of the intimate relation between its important types and syril1s, follows closely the spread of lues through ell countries. It is impossible to consider aneurysm as it is known to us today without an understanding of the part played by syphilis through all ages.

For brief consideration the history of syphilis may be roubly divided into four periods (3i): the firat extends from 1493, when syphils was first noted in Furope, to 1767, the year of John Funter's olassical experiment which he thought proved that eyphilis and gonorrhea were different nanifestations of the ocme disecse. The second or Eunterian perios extends from 1767 to about 1838 , when the separate identity of gonorrhea and gychilis was finally established. The third period includes the years following the establishent of the French school of syph110loky by Riccord, Rolle, and clerc to the discovery of the treponeme in 1905, of the Wassermann reaction in 1906 , and of arsphenamine in 1907. The fourth period or the modern era of syphilis extends from the years 1905-07 
to the present time.

The early part of the first of these four periods was one of extreme confusion. Syphilis was a new disease, appaling in the rapidity "ith which it spread end the severity of its manifestations. Medicine, dominated to a great measure by astrology, mysticism, nd superstitions, was hopelessly inadequate in meeting the challange of this unexpected plague. Consequently, it was blamed on "Divine "rath", the malfosition of the stars, or dominance of the wrong body humors (37). Fortunately, this confusion did not last long. The introduction of syphilis into Elrope occurred almost simultaneously with an awakening of interest in science and the development of a new approach to the problems of medicine. The leaders in this revival were attracted by the new disease, and shortly after its sppearance it was the subject of intense study by numercus able observers. In a comparatively brief time they began to dispel the superatitions with which syphilis was regarded by freserting an intelligent explanation of wany of its manifestations. The sequence of the early course of the infection and the frequency with which it was contracted by sexual contact were quickly understood. Extragenital infections were also recognized and carefully etudied.

Shortly after the return of Columbus in 1493 to Spain, 
Diez de Isla (cit. (39)), a physician of Andalusia stated that he had treated some of the ship's company for a new transmissible disease which bed appeared among the sailors a year previously and wille still in America. For scme years following, this phyxaician claimed to have had an opportunity of seing the spread of the disease and of studying cases in Lisbon. He collected his observations in a published work which appeated between 1510 and 1520. In this treatise he referred to the malady as the "diserse of the Island of Esparola", and commented upon the fact that the diseage was unknown in Europe before the year 1493. He found that the members of the shif's crew observed the fresence of the disease in the natives of the newly discovered land. In his royal report to Charlen $\nabla$, he stated that the disease was contacted from Indian women by the Spaniards th Columbus and was brought by them to spain.

One of the leading antagonists at present to this theory of the origin of syphilis is Holcomb (cit. (37)) who concludes as a result of 3 thorough and scholerly study of the pertinent medical and lay writings of the fifteenth and sixteenth centuries, and particularly those which appeared between the years 1491 and 1554, that eyphilis was prevalent in Europe prior to the return of Colurbus. Pussey (63) on the other hand, after an equally careful study of the same sources, believes they lend 
$-12-$

support to his contention that sychilis originated in America or was brought from America to Europe. Data gained from the exanination of the bores, particularly those of the skull and extrenities, of individuals tho died in Europe, India, and Egyft before and after 1493 and from the bores unearthed in the mounis and graves of American Irdians, is wuch less controversial. According to Pussey (63), Virchow, who was almost as noted an anthropologist as he was a pathologist, stated as late as 1896 that he had found no evidence of syphilis in the bones of Europeans who bad died prior to 1493. After that date, however, bones unquestionably sychilitic were frequently encountered.

As early as 1498 Villalobos (76) ouggeated that the lesions of secondery syphilis were infecticus, an observation that was overlooked for over 300 years.

Early in the sixteenth century both Fernelius and Pare associated some aneurysms with syphilis (39). However the Italian physicians at the end of the seventeenth and beginning the eighteenth centuries were really the first to lay great emphasis on the syrhilitic origin of aneury $8 m(57)$.

The first description of the gross pathology of syphilitic aortio disease was noted by Morgagni in 1725 (oft. (36)) and is as follows: "In some places whitish marks 
of a future ossification occurred; in others, some small foramina, as it were, bad begun to be formed; and in atill other places were paralleled furrows, drawn longltudinally; and in this manner was the surface of the artery unequal here and there".

The discussion on aneurysm by Lancisi in 1728 (42), the distinguished Boman physician, is much the best of those of older writers. He approabed the subject systematically, dealing witr its distribution, pathological anatomy, classification, and etiology. He appears to be the first cne to have analysed carefully the manner of develorrent and the part played by the contained blood of arteries acting upon diseased vascular walls. During his time the more frequent occurrence of aneurysm within the thorex led him to forrulated frinoiples which are applicable to the frobl am of aneurysm at the present time. He realized that there were many factor brought into play for the development of aneurysz. Lancisi states that persons doins hard labor as porters, ball players, eto. are more likely to have aneurysma due to greater force of the blood. He also eays that increased impulse of the blood, which gives rise to a "spurious aneurysm" can rarely occasion a true one unless at the same time the coats of the artery are generally or partially weakened, so that an eroding liquid may increase the power 
of this cause. He aprlied the terms "true and false", but not in the modern sense, snd described skeletal erogion by an aneurysual sac as an acrid fluid, oistiling fron the aneurysmal cyet or sac, which may penetrate as far as the bones or 11 gaments, which it may gradually corrode. He also discussed meroury as a cause of aneury 8 s. Further he believed that "Mercurial fluid" in the vessels cause distention of them much as it causes swelling of the salivary glands. Lanciai knew that aneurysm interfered with blood flow through the erteries which may cause gangarene of the extremities. He laid great stress on mental disturbances causing aneurysm, calling them hypochrondiacal and hysterical types. He recognized that the radial rulae in acrtic and great vessel aneuryams my be mall and irregular.

A. Monro (cit. (39)) in discussing the formation of aneurysm, 1733, depicted the manner in which traumatio lesions were associated with their occurrence. In his researches he was able to find only two or three specimens in which the wall of the aneurysmal sac consisted of the annuler muscular fibres, and this be believed was the only criterion whereby true aneurysm could be distinguished.

At about this time aneuryom appear to have been fairly cowwon in England, for William Eunter (33) in 1757 
reported his observations upon a number of them. He recognized three types of aneurysm: true by dilatation, false by rupture, and mixed; that is, partly by dilatation and partly by rupture. ye gave as his ofinion that aneurysul of the sorta was incurable. He recognized clearly the association of sychilis with aneurysm; but he did not think that this was the only cause of the aortic disease.

William Hunter (33) appears to have been the firat to recognize clearly the development of the arteriovenous aneury sm produced through blood-letting.' During the operation of venu-puncutre, the knife is by accident driven through the vein walls into the underlying artery. This; he found, led to the permanent establishment of a communication between the artery and vein.

A very interesting series of aneurysms was observed by Donald Monro (50) in 1760. Some of the lesions he recognized as ariaing in association with injury, while the internal thoracic type he believed of sontaneous origin. Nonro, by much careful dissection, was sble to show that true aneurymmay exist with the dilatation of all the coats of the arteries, or that the sneurysm way possess in its covering only portions of each layer. monro could offer no common cause for the majority of true aneurysms. Strainings of the body, an increased 
momentur of the blood, and a stop rut to its free circulaticn through some of the lare vegeels, has been alleged to give rise to severci. "Sometimes a scorbutic or venereal taint, or eome other acrimony in the bloodn has bèen accused.

Monro (50) remarked uron the frequency of aneurysms of the aorte near the heart, being almost equal to, if not greater than, those in all pther parts of the body together. It is still true today that aneurysms of sufficient importance to attract attention are for the most part located within the chest; nor has the type of aneury am described by lonro changed in any menner. The mode of death was possibly more frequent by ruvture in his time than in ours.

Advancement in the knowledge of syphillsicontinued with steady progress. By the beginning of the elghteenth century, or by the end of the first of the four periods into which Kemp (37) has divided the history of syphilis, syphilitic lesions of the bone, eye, skin, viscera, the aorta, the cerebral vesels, and the upper respiratory tract had been recognized and roughly classified.

The teachings of John Hunter (32) so completely cominated the second period of the history of sychilis that it is aptly called the Eunterian period. It is unfortunate that Hunter, one of the great men of medicine of 
all time, is frequently remenbered as the man who retarded progress in the knowledge of sychilis for at least fifty years. The controversy raised by Hunter concerned the dual etioloty of syphilis and gnorrhea. In 1560 Paracelsus (59) called syphilia "French gonorrhea", apparently because he thougt ginorrhee and syphilis were the same disease of different manifestations of the same disease. This conception was accefted without sericus question for the ensuing 150 years (37). However, by the end of the eighteentr. century there was an accumluation of evidence which injicated "that aychilis and gonorrhea were entirely different diseases which had in common only the frequency with which they were both contracted by sexual contact. Hunter (cit. (3r)) refuted this growing apreciation of the duality of the two infedticns by affirming they has a common etiology, and that the character of the surface upon which the virus was implanted determined whether gonorrhes or sychilis follows: that is, if infection occurred on a secreting surface such as the urethre, gonorrhea resulted; if, however, inf ction occurred on a nonsecreting surface such as the skir, syphilis resulted. In an effort to rrove his contention, Hunter inoculated himiself on the penis with gonorrheal pus and develofed syphilis and gonorrhea both. Unfortunately the individual from whom the inoculum was taken 
had both gon orrhea and an unrecognized chancre.

Comments made by Baillie (4) in 1789 uron aneurysms are very clear, and althou h he did not associate its development with lues, it is unquestionable that the specimens which he described were of this kind. He sald the wost frequent situation of aneurysm within the cavity of the thorax in at the erch of the aorte. He claimed that the reason why aneuryams take place more frequently in the arch of the aorta, than in any other part of the arterisl system, is its curvature, which exroses it to the full ingetue of the blood propelled by the strength of the left ventricle. Baille recognized that aneury in the arch of the aorta, as well as in every other part of the arterial system, hapren nuch more rarely in women than in men.

Lobstein (cit. (39)) in 1833, who is the author of the term "arteriosclerosis", believed that true aneurysm was not caused by the lateral pressure of the blood, but followed in the wake of arteriogclerosis. Aocoring to scarpa in 1805 (67) all aneury sms without aistinction arise through rupture of the arterial coats following upon their degeneration, no matter of what type, and that the sac is formed by the dilatation of the external coat of the artery. In other words, he believed that the aneurysm was not contained within the true arterial wall, but only 
vithin a snall portion of its exterior. Lobstein disagreed with this, inamuch as the theory was not applicable to diffuse or fusiform aneurysnis. Dubois and Dupuytren (cit. (39)) found that the internal cost of the artery was alvays extended over the inner surface of the aneuryamal $\mathrm{sac}$. Laennec (cit. (39)) in the early part of the nineteenth century, recognized the great damage which was done to the midale coat of the artery and observed the disappearance of the muscular tissue in its structure. His means, however, to obtain a thorough understanding of the extensive destruction which takes place in syphilitic aortitis were limited.

It was the medical officers of the British army who forced the recognition of the part played by the disease sychilis in aneuryms upon the attention of the profession (57). Unfortunately, many of the communications were buried in Annuel Reports which never had the proper: recognition.

A very important communication was that by InspectorGeneral Lawson (cit. (5\%)) in which he pointed out the great frequency of aneurysm in the British amy, and its increase at Aldershot from the ration of 0.25 in 1860 to 1.68 in 1868. Olser says that he believes Lawson was one of the first to recognize clearly the independence of aneurysm of the ordinary atheromatous changes in the 
arteriea.

Klotz, (39) also gives medical officers in the British army the impor tant credit in recognizing the intimacy between syphilis and aneurysm. "These men," he says, "Crisp in 184\%, Lewer in 1862, Aiken in 1866, Laweon in 1868, Myers in 1870, and Welch in 1876, presented irrefutable evidence by the demonatration at autopsy of the common presence of aortic disease in known syphilitics and by showing the staes of development of the aneurysmal fouches in these luetic aortas." Sychilis amongat soldiers had always been ac cepted as high in incidence but it had never been so forcefully shown that the infe cted group had a definitely high percentage of internal aneury sm.

The work of Criap (12) was of particular importance, as it was the first monograph in the English language dealing with the subject in a general manner and based upon a large number of cases. Fver at this time, 1847, Crisp was able to collect 551 cases of spont neous aneurysms from the British medical journ 18 between the years of 1785 and 1847 . The cases were carefully analysed as to the aistribution upon the arteries, the age periods of 1785 and 1847. The casen were carefully analysed as to the distribution upon the arteries, the age feriods offoccurrence, sex, and history of syphilis. Crisp elso 
believed that mercuricl posioning, passions of the mind, blows, and lifting heavy burdens were crigins of aneurysms. He wrote leters to medical men the world over determining the incidence of aneuryams and found that in India and in the west Indies aneury ans of the natives were fractically unknopn. He offered no explanation for this phenomena.

Welch (79) in 1875 presented data attempting to prove that syphilis was the cause of aortic aneurysm in $66 \%$ of 52 cases of aneury sy found at autopsy in soldiers. He described his gross findings, and stated, "this disease of the aortic coats may retrogrese-- but if extensive or severe, as a rule it is followed by one of three fatal phases; formation of aneurysms, implication of aortic valve, or hypertrophy with or without dilatation of one or more of the heart's cavities". The paper was very unfavorably receivel and its discussants, openly expressed their unbelief.

The importance of syphilis was thus well established by the latter part of the nineteenth century, although in sowe quarters the part played by arteriosclerosis, bigh blood pressure, anomalies of structure, and other infectiona, was still maintained to be equal to ita influence in the origin of aneurysms (39). The microscopic differentiation of the sychilitic lesions from 
other forms of disease had not yet been made and the calsation of the infection was not yet discoered. However, the theraceutic teat as shown by the French authors, Fournier, Vallin, Verdie, and others, as well as reports by Muelhaus and Schmidt in Germany, gave further support to the syphilitio nature of the process (cit. 39)).

There were a good many exceptions, and the view has gradually gained acceptance; and in 1894 Gooshart (cit. (57)) made the atrong statement that "It is sufficiently near the truth to say that women never have aneuryam except they have had syphilis". Virchow and cthers in Germany, Lancereaux and others in France, were strong supporters of the sychilitic view. The Dublin physicians, whose contributions to the subject of aneurysms have been so important, described many cases associated with syphi1is. Sir Samuel Wilks (80) was the first in Britian to recogrize the importance of eyphilis in arterial digease, and in his well known paper he described the characteristic syphititic arteritio of the cerebral vessels. In 1868 Sir Clifford Allbutt (cit. (57)) studied the bistological changes in the arteries in case of cerebral syphilis.

An important work which is frequently overlooked is that of Barkow (cit. (39)) who published three unwieldy volumes in 1869, 1871, and 1872. Although this author did not discuss the importance of syphilis as observed 
by him, his drawings show syphilitic lesions of the aortic wall in many cases where distortions and dilatations occupied their course.

The discoveries which opened the fourth period of the history of syphlis ocourred with starting rapidity. In 1905 Fritz Schalidinn (cit. (3?)) discovered the organism of sy hilis, the tre onema pallieum; in 1906-07 Wassermann, Neisser, and Bruch, And Detre (78) announced the discovery of a serologic (complement fixation) test for syphilis; and inally in 1907 Ehrlich (13) discovered arsphenamine, and two years later released it for general use for the treatment of syphilis.

Another important event in the history of syphiletheracy was the introduction of bismuth by sazerac and Levaditi in 1921 (cit. (39)). Oarrying on the promiang work of Sauton and Robert, intermuted in 1914 by the wa, tevaditi and his co-workero made extensive experiment 1 studies of many bismuth preparations. Their report of satisfactory clinical results following the intramuscular administrations of sodium and fortassium tartrobismuthate was promrily confirmed. 
PATHOLOGY

Before the discovery of the circulation of the blood in 1628 adequate understanding of the pathogeny of aneurysm was impossible (11). The real story of syphilitic aortitis begins in 1876 when Erancis H. Welah (oit. (40)) a pathologist at Netly, England described for the firat time, its essential macroscopic and microscopic features, and pointed out quite convincingly its relationstip to syphilis.

For some years before this it had been held that syphilis played an important role in the production of aneurysm. Ambrose pare in the sixteenth century was the first to suggest this. Lancisi in 1728 spoke of a venergl aneurysm, and Morgagni in 1761 gave ample evidence of the importance of syphilis as a cause of eneurysms.

Welch, however, was the first to demonstrate the actual patholog and to lay the foundation for a regl underatanding of the disease as it affects the aorta. His publication was strongly contested, then forgotten. Ten years later Dohle (cit. (40)) published a comprekenaive report on the disease which arousedinterest in the disesse again and confirmed Welch's work.

The demonatration of the same process in a high per centage of syphilitic fetus and the finding of the trepamona pallidium in secticns of syphilitic aortas by 
Rueter snd Schmorl in $190 \%$ (cit. (40)), the introduction of the Tassemann feaction (78) with its high percent of positive results in these cases, were further mile stones in establishing the knowledge of syphilitic aneurysm and aortitis on a firm basts.

if we think of an artery as having all the coats of an automobile tire, we are able to understand the mechanism by which syphilis worka such frightflil damage to the arterial system (1I). Now the rubber on the outside casing may wear right into the fabric (media) and we will conaider this outside rubber as the adventitia. As long as the fabric of the cas ne is intact the air inside the inner tube (intima) will be in no danger of bulging through the other coats causing a blowout. Let a lesion (cut) go through the fabric and there is trouble at onee fror the elastic pressure within. Syphilis cuts the musculo-elastic tissue of the media and the reby makes posaible the bulging of the other coats through the rent. How? In the larger arteries, that is the thoracic and abdominal aortas, the vessel wall is nouriaked by means of the vasae vasorum. In the smaller arteries with their thin coats, nourishment of the arterial tissues takes place both fom within and without being as it were laved in plasma by means of the lymphatics. In arterial oypuilis involving the aorta let ue say, 
the changes begin in the adventitia an $d$ pass back into the media. In a fully developed local lesion we find the media infiltrated with round cells. Lymphocytes and flama cells form along the area nourished by the vasae vasorum. so that, looked at from the internal side, we see these elevated patches due to the accumulation of these cells and their organization into fibrous tissue. This fibrous tissue takes the pace of nonstriated muscle and elastic tissue of the media. Instead of expansile tissue destroyed by the miliary gumma now have an area of artery with the "fabric" replaced by scar. It is through this area of mesarteritis that the aneurysm bulges.

When these areas are close together the srtery may bulge as a whole. If the damage is not so great we may get little saccules which are the beginning of sacculates aneurysm. Syphilis is the only disease which gives this widespread change in the wedia (11).

The most important change is the result of endarteritis and periarteritis of the smaller arteries, in association with infiltration of lymphocytes and plasma cells around them, these changes being brought about by the presence of treponemes in the aduentita. This is the cale ever syphilic disease occurs and when the aorta is attacked the lesions are essentially in connection 
with the vasae vasorum apearing first in the adventitae and then invading the redia. Owing to the important results in the latter, the lesion is sometimes sroken of as sychilitic mesaortitis. The initial lesion is the formation of a plaque or area of thickening in the intima, of rreyish-white color and somewhat translucent appearance: Such flaques are often of considerable thickness and show little tendency to degenerate. Later they extend and fuse together forming areas of somewhat wavy or slightly wrinkled aurface, while the intima in the parto between may be healthy in appearance. At places, absorption and contraction of the tissue may occur with formation of cicatricial tissue which oxsoionally has a somewhat tellate form (II).

Localized depresaions which are potentially the commence ment of eneurysms, may sometimes be seen. At a later reriod of life, the yellow patches of atheroma may be gesociated with syphilitic lesiors. The aortic arch is by far the commonest site of syphilitic lesions and they are sometimes restricted to it. The part of the arsh immediately above the aortic valve is usually involved first and disease may have two serious results. It may lead to narrowing of the orifiees of the coronary arteries or it may spread to the aortic cusps, froducing thickenin of them and resulting in incompetenoe of the valve. In this way syphilis is often the cause 
of important cardiac disease and disturbance. The lesions occur, toc at a lower level, but it is not uncommon to find that they cease at the point where the aorta passes through the diaphragm. Sometimes, on cutting through the aorta, one may find evidence of the extension of comparatively soft, or even gumatous tissue from the outside, but as a ruie the characteristic changes in the adventitia can be detected only on aicroscopic esamination.

The earliest histological change, then, is to be fcund as a cellular infiltration around the small vessels in the adventitia, attended by periarteritis and endarteritis. The infiltration then extends along the vessels into the substance of the media, snd at places widens out into irregular cellular areas, in which there is also a new formation of thin-walled vesels(II).

Syphilitic aortitis, the precursor of aneurysms, with rare exception begins in the supra sinus aort jast above the aortic valve (54). It may remain localized as an uncomplicated aortitis; or more often, it extends downward to involve the commissures and valves in rather a typical manner. The ascending aorta and aortic arch are well oupplied with lymphatics and the invasion of the aorta occurs through these lymphatics accompaning the vasa vasorum.

Syphilitic aortitis is first to be looked for in the 
ascending aorta (39). Next, most commonly we find that the lesion lies in the arok and, following this in lesser frequency, win the thoracic aorta. In almost all inotances where the erch or the thoracic aorta, or both, how a sychilitic process, we find that earlieat damage hes occurred close to the heart. It is remarkable to note that in the majority of cases of gyilitic aortitis within the thorax, the lesion seldom goes beyond the diaphragm. It would appear that the virus does not find ready access to the lymphatio channels lying beyond this structure. It is likewise interesting to observe that a s yphilitic aortitis involving the arch frequently leads to an extensive nodular overgrowth about the mouths of the vessels entering the neok and yet failo to enter these vesiels themeelves. Klotz (39) states he has repeatediy seen healthy carotids and innominate artery attached to a seriously diseased aorta.

The abdominal aorta is but seldom involved in a syphilitic process. When it does occur its most common site of develorment is about the coeliac axis which is the point where the abdominal lymphatios centralized about the aortic wall and encirole it in a rich network of lymph channels (39).

The ratio of aneurysms in the various portions of the aorta is approximately 10 ascending, 7 arch, 3 descending 
and 1 thoracic in over 3000 cases reviewed by Boyd ( 7 ). Aneurysm of the ascinding aorta has been divided into two types: of the intrapericardial portion (aneuryom of symptoms) and of the extra pericardial portion (anemrysm of physical signs) (54). In reference to the first type, it should be noted that they are usually found at the sinus of valsalva upon the right anterior surface of the eorta. These aneuryams of symptons are prone to rupture before manifesting marked physical signs uhless aortic regurgitation complicates. The symptoms are those of aphilitic aortitis. Bince the second type has large sacs which displace and compress neighboring structures, they have been denominated "the aneurysm of physical signs".

Aneurysm of the arch is another aneurysm of symptoms. They are usually found upon the posterior or posterior inferior part of the vessel and tend to involve the orifices of the innominate artery. The usual growth is backward so that the various vital structures in the vicinity of the doral surface suffer early. Anterior growth causing midline tumor is knowr but is not as common.

Aneurysm of the upper descending aorta is an "aneurym of latency" ( 7$)$. In spite of the many possibilities for the production of respiratory, esophageal; , or vertebral 
symptoms, this type is especially lieble to be overlooked. The frequency of failure to discover aneurysms of this nature is due to the fact that the findings are frequently to be discovered upon the back; the examination of which is usually minimized. Anterior growth in the left subclavicular space is known. It should be emphasized that the locaticn of the sac in the verious forms is not pathognomic but only suggestive.

Aneurysm of the lower descerding aorta is another aneurysm of latency differing from the above in merely the greater liability to pleural or lung rupture and a rarity to esophageal ruxture.

The luetic process produces a weakening of a diffuse segment of the aortic walls, resulting in aneurysral dilatations of two types: fusiform, vibich is produced by a diffuse luetic infiltration with thinning of the walls and intact arterial layers, (it is infrequent in occurrence and runs a benign course without pressure phenomena) and, saccular which is a luetic infiltration with thinning of a discrete portion of the aorta (55). This type may remain benign until rupture of the aortic wall takes place. Then, if situated near an important viscus such as the left bronchus, early pressure symptons occur. Later there is more or leso extension of the aneurysmal sac; the outer layer of wich way be adventitial or peri- 
adventitial tissue. There are then produced adhesions to, and disflacement of, imfortant structures, fistulous openings into hollow viscera, and sudden large hemorrhages.

In the ascendine sorta and arch, saccular aneurysms ocour more frequently at the convex and posterior surfaces, beause theik farts are subject to greater hydrostatic strain from the moving column of blood.

Dynanic pressure and disflacement of structures, adhesions or fistulae to neighboring organs, decend on 10cal anatomical relations and the extent of the aneurysmal sac. One formed, the aneurystal sac expands progreseively usually outward from the artery following the lines of least resistance until it meets with some obstruction (25). The higher the blood pressure the more rafid the dilatation. When the wall of the sac presses upon neighboring tissues, it begins to erode then. The pressure acts in the fol cwing way: It cuts off blood supply to the neighborhoodbecause the pressure within (aortic) is greater than smaller vessels. Necrosis takes place from the compression and the products of necrosis are absorbed by the cells in the tissues of the very vaccular wall of the aneuryam fast as they are stained. Bone tissue too is absorbed by action of the ostecclarts, and the wall of the sac thus advarces through the chest wall very much as a tumor wight do. It goes through bones, muscles, 
nerves, other vessels, etc. always being forced in a ot raight line by arterial pressure in aorta. Hence aneury am usually points in the direction given them by the impact of the blood stream: those of the descending aorta pointing tothe right; those of the arch pointing backward and to the left. However, resistance of the surrounding tissues and especially local thinning of the aneurysm wall may cause its course to be defected somewhat from these typical direations.

of all the eneurysm of the aorta producire epinal cord compression reported in the literature as fad as can be determined were of syphilitic origin (71). Only one in 100 to 20 e erode the spinal cord but about one half involve the bertebrae. The compression and resitant clinical symptams may be due to any one of three occurrances: The aneurysr may produce di rect pressure on the cord; an epidural hemorrhage due to wupture of the aneury mal sac may result or the weakened bone structure may collapse and pinch off the cord. There is no case on record where the dura has been penetrated. It may however, be involved in adhesicns to the aneurysmal sac. The micro organtim of eyphilis, like that of tuberculosis possesses the remarkable ability to survive over long periods of years in the human body without producing demonstratable physical signs or clearly defined subjective syrotom (54). 
From the pathological standpoint, it was th ought interestine to note the tive interval between the infection and the production of the first aymotoms of eneury $s$ ( 7 ). This was noted in 200 cases and it was found that the average time was twenty years, which corresconds in general to the upper linit of the maximum time interval for syphilitic aortitis. The minimum tine was one year (ay hilitic aortitis $h-s$ been recorted in six months). The upper linit was fifty-six years after infection. In one case beginning aneurysm was found at autopsy when the chancre was atill on the penis. The importance of these figures outside of sbowing the ugual time interval is to emphasize that the syphilitic indivicual remains throughout his life potentially aneurysmal.

In 150 cases at the Cleveland City vospital there were $68 \%$ wrich occurred in the fourth and fifth decades of Iife (17).

It is emphasized by Kampmeier (36) that age in itself is a minor factor and it is the latent period between initial infection and the signs and pathology associated witr cardiovascular syphilis that is inportent.

'Aneurysm of the thoracic aorta is 5.6 times as common in ales as in females ( 7$)$. All statistics give males a marked predominance although the figures vary from 10 to 3 up to 11 to 1 . 
Aneury $8 m s$ may be seen at any age. It has been reported in the infant and in the very aged. The curve of incidence rises slowly from birth and reaches a maximum in the period form thirty-six to forty years and then falls more slowly. While aneuryem is usually discovered in the years of greatest physical activity, it must be considered as a diagnostic posibility at any age. In 3690 cases, the exact age was stated and 1 rig or about $75 \%$ were between ages of thirty and sixty. The colored race is notoriously liable to sneury am, probably due to the increased incidence of syphilis in the race and neglect of treatment. occupation requiring adden violent exertion precipitates many latent aneurysm but probably joes not cause theri. It is probable that the association of syphilis, elcthol, and hard work in the same type of individual is more infortant than occupati on iteelf, although there bes been a sufficient number of sneurysms found inmon-syphilitic children(usually suffering fror: whooting cough) to warrant the view that stress and strain play wore than a winor part in some cases."

However Eirschfelder (25) says, "No change of pressure during life is sufficient to dilete an artery to the porportions of even the smallest aneurysm". According to the elasticity curve of Roy (cit. (25)) the dilatation 
occurring between 120 and $110 \mathrm{~mm}$. He. is about $20 \%$ of the dianeter of the artery, and the results of Grehant End Qunqueud (cit. (25)) show that little furtrer dilatation occurs or righer cressures until the artery ruftures at a pressure of 1680 to $4530 \mathrm{~mm}$. Hg. 10-20x blood pressure during life.

Recently Katz and Simpson (cit. (29)) subjected fresh aortas from cadavers to 1000 to $3000 \mathrm{~mm} \mathrm{Hg}$. without rupture.

Dr. Osler impressed upon his classes the essertials of cause in the froduction of aneurysm (11). Venus, Bacchus and Vulcan constituted his etiologic triad. The importance of Vulcan has been underestimated. Natives of the troxics with plenty of Venus and Bacchus but too lazy to work do not have aneurysne very fiten with their syphilis. Te night add Mars, the fod of war to noler's three for war has al ways been the great spreader of syphilitic infection. The greater the incidence of syph1Iis in populaticns "addicted" to beavy work the greater the incidence of aneurysm.

Although the trefonema pallidum has been repeatedly demonstrated in the aortic lesions and in the tissues of the wall of the aneurysm the organism is not always easily found (39). This parasite doesn't permeate the injured areas in the aorta, nor does it persist in the 
old scarred areas. We heve discovered it mainly in the advancing bor ders, groured in small clusters about the inflamatory reactions near the vasa vasorum.

There is no longer any disfute about the definite relationship between the type of aneurysm which we are discussing and syphilis (40). Definite though this may be it leaves us in the dark on three points:

WHY is there the peculiar predilection for the surrasigmoid portion of the aorta?

WHY the extremely lon \& latent feriod, approximately 20 years, between intial infection and the appearance of cardias sign and sympotms?

WHY the difficulty in demonstrating the trepamona rallidurn in the aortic lesion even when the disesce is well advance d?

While various theories have been discussed by different writers, no convincing answers bave been forthcoming. It is perbaf better to recognize the fact these re still unsolved fr oblems at the present time. 


\section{SYMPTOM ATOLOGY}

With the develorment of an aneuryems a group of gymptoms due to the pregsure of the aortic tumor aprears, and a number of characteristic physical gigns become evident $(77)$

Symptomaltolgy was noted in 1011 cases by Boyd (7). Pain, a chief complaint, was locsted in the chest, left shoulder, right shoulder and in the back. For this reason the location of the pain should not be considered diagnostic.

The character of the pain varies a good deal, manifesting itself in one of three form (58). Anginoid rain , occurring early in the disease, is associated with aneurysm of the sinuses of valsalva or the ascending aorta. Opinions as to the caure of the pain are: stretching of the aorta; and presure upon the coronary arteries. According to Mills and Horton (49) the angina pectoris is associated with intimal overgrowth at the orifices of the coronary vessels. This pain is often radiated down the arm and associated with numbness or tingling of the fingers and exertion is esfecially apt to provoke an attack (48).

Pressure pain is the typical pain of aneurysm, but is not present until the growth reaches the chest wall. Many witers have noted that patrodue to erosion of the 
ribs and sternurs is much less marked than erosion of the vertebra. Rarely this erosion of bone takes place without pain (77). In adition to erosion, presoure pain $m$ may be seen when there is involvement of nerve trunks. Aneurygm of the descending aorta may present themselves under disguise of an intractable neuralgia. This is particularly liable to lead toother sensory disturbances in affected areas.

The third type of pain is difficult to name and occurs in disgecting aneurysm. It is sudden, terrific pain in the chest, usually associated "with collapse from which the patient may or may not rally" (7). When cases live for more than few minutes, they present usually the clinical picture of severe angina pectoris and in a short time, hours or days, they have a second attack and death: occurs.

Dyspnea is a common symptom seen in a variety of degrees and types. Boyd (7) places it second because in its milder forms it is apt to be disregarded by the patient and elicited only upon inquiry. In its mildest form, it consists of a mere substernal oppression; it is increased upon exertion and indistinguishable from syphilitic aortitis. More severe is the form due to pressure upon the trachea and large bronchi. There is a paroxymal type of dyspnez which is very important. 
These attacks may be occasioned by changes in posture and the patient often assumes unusual positions in order to avoid their production. The cause is not known, some attributing the symptom to pressure upon the vagus, others the recurrent laryngeal, but whatever its ultimate etiology it is rarely seen unless there is actual pressure upon the trachea or large bronchi.

Cough is a cormon symptom of aneurysm is a laorge number of cases, seen in association with "attacks of rolda". The typical cough accompanying the colds is a harsh, .? brassy cough. Hall (2z) compares it to a leopards growl or a rough, glutteral cough.

usually when cough is present, there is little or no sputum. When arch or descending aneuryems press upon the left bronchus, a large amount of sputum may be noted (7). When sputuri is present, tt is modified in about one-fourth of the cases by the addition of blood. This bleeding may be of three types: A large hemorrbage due to ulceration through the left bronchus or lege commonly the trachea which is fatal in a few minuteg; a group in which profuse hemorrhages are seen over a period of months due to leaking of the aneurysm and subsequent blocking of the rent by means of a clot; congestion from a failing mycardium, pressure, pulmonary infraction, or actual rupture into the lung substance. The last row occure just before 
death.

Tumor is at times the chief complaint, and its intensity depends on the situation, the rapidity of growth, and its size (58).

Dysphagia is a symptom closely allied to dysphonia. In arch eneurysms it is froduced by pressure through the recurrent laryngeal nerve and spasm of the esophagous, which is apt to be transient (77). The lower the aneurysm is upon the descending aorta, the less freqnent is dysphagia. As a chief complaint it is not common and is rarely complete.

Loss of weight and $108 \mathrm{~s}$ of appetite are symptoms present only in those cases which have lasted over a long period of time. Loss of weight may be due to a number of causes as pain anywhere in the thorax, pain on swallowing and more rarely pressure upon the thoracic duct (7).

A large aneurym may press on the esophagous and interfere with entry of food into the stomach, or compression of thoracic duct may cause engorgement of absorbent. vessels and glands and lead to great interference with nutrition (2z).

Among the most important objective phenomina is found pulsation. The first type of pulsation is the iffuse general shock that may be seen anywhere in the chest, 
espec ially frequent in ascending aneury complicated by cardiac hypertro hy due to a concomitant aortic regurgitation (7). The second type of aneuryamal pulaation 1 s diffuse with no distinct shock noted. Pulsations are most frequently noted in the second right or left intercostal spaces or in the back. With the exoption of the last, pulsation is not in any way charactteristic of aneurysm.

Aneurysm irritating the superior cervical sympathetic may show dilated pupils, widened slits, pootusion of the bulb, or in the state of paralysis ray be seen miosis, exophthalmos and sympathetic ptosis. Changes in the size of the fupils may be caused by vasoular conditions. More important than dilatation or contraction is anisocoria. Due to this sympathetic irritation aweating and increased redness of the face and in some cases chest and right arm may be present (58).

Involverent of the recurrent laryngeal nerve is a frequently overlooked sign because of inability to make the examination or neglect to do so (58). When involved, it usually is the left that is disturbed and as a rule the cord may be paralyzed a considerable length of time before there is any volce change. Later when the cord passes back into the "cadaveric" position the various types of dyaphonia appes ( 7$)$. 
It has beens sid that More miatakes are nade from want of looking than from want of knowing", and in no complaint is this more true the $n$ in aneurysm ( 22$)$. Diagnosis of aortic aneury sm is notoriously confusing because of its resemblance to snd similation of other chest pathology. And espcially the condition is often mistaken for heart disease (58).

Dy nes, thoracic pain of the various types described heretofore, respiratory, circulatory, laryngeal, paraplegia, heriplegia (erosion of the vertebrae) and general symptoms are those by which aneurysm is usually diagnosed along with the more or lese well known physical findings (22).

In the absence of rulsation or swelling, pain in the precordia is often diagnosed as angina fectoris. Pain in either shoulder or back is often disignated by the confueing and meaningless term "rheumatism" which heads the list of wrong diagnoses. Pain in the intercostal spaces is often labeled neuralgi: where by a symptom is confused as a disease. Pulsating emryema has been mistaken for an aneury om which has eroded the ribs and caused turor on the thorax. Dysphonia rarely causes diagnostic jifficulty because this symptom is rather well understood. In a few cases the diagnosis was 
Amoré general diagnostic points both De Haveland Hall and Mills and Forton (49) report clubbed fingers, bruit, trrill, and abnormal heart sounds. Hall (22) also reporte a method of finjing trachael whiff by putting the stethascope in the patients mouth and in arnea, bearing a "sybtolic whiff" when aneurysw is present. Tracheal breathing especially with stridor is an important clue in detecting aneury $m$.

Anisorcoria, 108 of reaction to light and accomaration, miosis or dilatation of the furils may be caused by the aneurysm interfering with the symathetic nervous systen, or may be due to tabes (22).

Some of the reascne for making wrong diagnosis have been suggested by Boyd as noted in 130 cases (7):

Rheumati sw Tuberculosis A sthine: 32 22 Chronic Bronchitis 14 Rericarditis, pleurisy, carcinoma of stomach and esophagus, chronic laryngitis, tuberoulous laryngitie, abscese of the lung, pleural effusion, and empyema each $a$

A group of radilogists (55) give the most frequent errors in diagnosis as those concerned with pulmonary tuberculosis, asthma, chronic bronchitis, congestive heart failure, mediastinal neoplasm, pleuridex, antina pectoris, and c roinoma of the esorhagus. From a purely clinical standroint, it is easy to appreciate why such errors arise, since these conditions may produce aynptoms sinilar to those caused by aneuryms of the aorta. 
Rottgenologists have felt that every ouspected chest condition, from whatever cause, should be subjected to careful roentgenoscopic and roentgenologic study and that this closer cooperation between clinician and roentgenologiat, with the latter acting in a consulting capacity, will result in more accurate diagnosis (55).

In 1898 within short time after Roentgens discovery in $1895 \mathrm{Xray}$ sere used to diagnose cardiac enlargement Nacentyre (cit. (65)) was first to wite of the use of Xray in diagnosis of intrathoracic areury $\mathrm{sm}$.

It would be well to emphasize that not all aneurys of the aorta are accessible to roentgen study (55). The exceptions are represented by the type arising from the sinuses of valsalva and the small pouch tyre. But even here the roentgenologist may be of great assistance in raising a sustioion of their presence.

It is interesting to note that a group of roentgenologists say, "we believe that there are no classical pathognomonic symptoms and physical signs of aortic aneurysm and that, while the diagnosis is very often clinically correct, the services of the roentgenologist are of inestimable ald in confiming or ruling out the presence of such a lesion". Obviously the roentgenological diagnosis is the most important part of the examination since size and location are thus accurately deternined. Many 
aneurysms were first demonstrated by the roentgen ray, and changes in the lungs and related structures which clinically had been thought to be primary were thus shown to be secordary in nature. Dulsations may be seen; but, in our experience, differentiation between expansile pulsations and motion trangmitted form the heart has been inpossible except ir isolated instances. In fact, the great najority of aneurysu do not fulsate, becuase of disease in the rall, calcification, or the fresence of a mural clot. The differential'diagnosis of mediagtinal and lung tumors s at tiwer difficult. An aneury sm may reserble a tumor in the euperior mediaetinew, farticularly a oubsternal thy roid. The latter, however, moves upon repiration, awliowing, or grunting and the acrtic arch is dietinctly separated from it. An enlarged right lobe of the thyroid froduces an archlike displacement of the traches, with narrowing of the lumen, most marked in the region of the niddle superior mediastinum. The left lobe of the thyroid displaces the trabhea to the right. The lymphoblastoma grour of tumors; such as Hodgirs's isease, Iymyhosarcoma, leukeria, and thymone, are usually situated in, the anterior mediagtinum, and the trachee is very seldom disflaced laterally. If tre tumor is large enough, there my be a posterior displacement of the trachea. The aortic arch (without adequate films) can usually be separated fron the media- 
stiral mass. These turior masses are bilateral, enlerged in the vertical diameter, have inistinct cutlines, and rarely skow calcification (55).

A sidelight uron this subject is given by Evarts Graham (21) who reports two ceses of congenitial aneurysm of the ductus arterosus. Roentgenologists visulized a tumor in the surerior mediatinum, vith no pulsation. After operating on these two and loosing the first ons by functuriat the tumor (he was more cauticus on the sec nd one) he concluded that absence of pulsation is of no aignifiance in mediastinal tumors.

Another roint in diagnosis is that some thobacic saccular aneurysms froduc e characteristic erosion in the anterior and the lateral suffaces of the bodies of the vertebrae, (55). Because the intervertebral discs resist the destructive process better tran the bodies of the vetebrae, the rortions of the bodies nearer the discs are very little involved, producing scaphoid erosion of the bodies with intact overhanging edges. An infortant finaing in aneury sms of the terminal aroh is an irregular e rosion of the fourth and fifth thoracis vertebrae. It is necessary to note that the erosion is best shown in silhouette in the right oblique posiolon.

Singleton("ra) used infections of $\mathrm{NaI}$ with rapid roentgen ray exrosure on a sensitive flate with aneurysm of 
the ropletial, bracheal and fenoral. The irformation gainec was invaluable in regard to blood vessels entering and leaving the aneurysm and collateral circulation, which may be of great assistance in determing method of treatment. With more investigation this may be a valuable adjunct to the present diagnostic methods. 
PHYSIOAL SIGNS

noler (5e) says that good light, good eyes, and a certain metrod of routine are required for 2 successful examination. He states the patients are young, or rididle ated vigorous-looking subjects. Ho notee cynolis, inequality of furils, distention of veins o: the neck, and noticeable thoracic pulsation or tumor pulsation, or non-rulsation as important signs in inspedtion.

A very important finding of falpation is variation in the pulse (i). From a theoretics standroint the pulae in the aneurysmal sac should be later than the apex impulse but sirce the time interval is so short this sign gives practicallyilitle irformat on.

Harvey in the De Motu Cordis (cit. (65)) commented on the difference in the culse on the two sides. However pulse tracing is rarely d ne unless other signs of anerare manifest.

The complete absence of pulsation in the radial, brachial, and carotid arteries bilaterally is a rare condition. A study of the literature shows only five such cases and only in three was there an autopsy (47). In all of these cases the clinical ficture was that of attacks of dizziness and syncope together with absent pulsation in the upper extremities and neck.

Tracheal tugging was first described by Surgeon Major Oliver (56) in 18\%8; he says, "place the patient in the 
erect postion and direct him to elevate his chin to the fullest extent; then grasp the circoid cartilage between thumb and forefinger and use gentle upward pressure, when, If dilatation or aneurysm expt the pulsation of the aorta will be distinotly felt transmitted through the trachea to the hana. The act of examination will increase laryngeal distress should this accompany the disease".

Tracheal tugging is almost pathognomic of aortic aneurysm but may be caused very occasionally by anything which brings the aorta into abnormally close contact with the left bronchus. So neoplasm here has been known to show this phenomena and also fibrosis of the lung, so it must be used with other eyrmtors (2Z).

Von Glahn ( 77 ) states that tracheal tugging is very imrortant and that it should be searched for carefully because of the frequency with which it is present in aneurysm and the rarity which it occurs in other medistinal tumors.

Examination by ausculatation of the heart may show the signe of aortic regurgitation, which often accompanies sinus aneurysm. As to the aneurysm proper there are several factors which make for variation in susculatory findings. Adventitious soudd depend upon the contents of the sac and the conditions of the orifice. Among the positive findings one notes a dull first sound followed uy a ringing accentuated eeoond sound ( $(8)$. 
In percusaion we have a most important finding, namely dullness. In a majority of instances it is sub-or parasternal $(7)$. Aneurysms of the sinuses of valsalva may never reach sufficient size to give rise to change in duIlness. However, ascending aneurysms with treir large sacs will usually give rise to dullness to the right of the sternum. Arch aneury ang when not too deep will give rise to substernal or left paraternal dullness. However, mere dilatation of the aorta may give rise to this phenomina. In desceding aneury ams the dullness may be found in the subclavian space, the axillary space, or more commonly, in the left interscapular and left subacapular space. Rarely posterior dullness is mentioned in case reforts although nearly every text-book emplasized it. Von Glahn ( $r 7$ ) states that even large aneurysms can be present without imparement of the percuseion note. 
TRFATUENT-INEDICAL

Even today our diagnostic ability frequently exceeds greatly our ability to aid the patient gy treatment. There ia, however, a paradox concerning the early therapy of arifilis that is difficult to understand. The first period of the history of syphilis was characterized by surprisingly accurate observations of the manifestations and the clinical course of the infection. It is difficult to comprehend, therefore, why the same clinical acumen did not more quickly evaluate the arugs used in the treatment of the disease. Guaicum, China root, sarsacarilla, saseafras, and wany other preparations enjoyed longer periods of popularity than the clinical results which followed their administration justified (27). In contrast, mercury, the only drug introduced during this period which is atill used in the treatment of syphilis, held a very insecure flace. This was mainly because of the failure to evaluate clinically its effect uron the course of the disease when given in tolerated amounts. The bistory of its use in the treatment of syphilis is of interest in 1llustrating this point.

By whom and why mercury was first intcoduced is still obscure. Although Paracelsus (59) is frequently given credit for its introduction in 1858, there 18 abundant evidence that it was used at a much earlier date. 
Schamberg snd wright ( 58$)$ state that it was first pre scribed by midman in 1497 . It has also been stated that its value in the treatrent of sychilis was iscovered acoidentally as follws: "For some years before 1493 an cintment known as Ungusntum Saracenicum, which containei a small amoutn of mercury, E nintr part, bad been used with apparent sucoess in the treatment of scabies. Because of the clinical regemblance of some of the skin lesions of the two diseass, it was thourht that this ointwent might also be benefinicial in the trestrent of syphilis. When, as judged by its effect uron the skin losione of late sy hili s, this assumption proved correct, meroury was added to the othen antisyphilitic aruge in use. Immediately it was found to be of value, werourial ointments containin as much mercury as could be inoorporated in then were prescribed in the treatment of syphilis. Since the efficiency of mercury was judged to be in direct proportion to the severity of the reactiona it produced, win ivitis with $108 \mathrm{~s}$ of teeth, hemorrhagic gastroenteritis, and acute nephritis frequently and death not infreuently followed its adrinistraticn. It is not surprisine that the meroury cure of syphilis was dreaded wore than the disease and the drug fell into almost universal diorefute. As early as 149?, mercury was sounly condemed in the treatment of syphilis, and 
from 1580 to 1655 inedical students at Feidelber were forced to tak osth they would never presoribe it for that furrose. Paracelsus (59) who was credited in France with the introduction of the arug in syphilotherapy, was labeled "the mad man from Germany".

It was more than 250 years after the introduction of mercury before it was croperiy used in the treatment of sy hilis. In 1750 Venswieten (74) who introduced the use of mercury bichlorite orally in the treatment of syphilis showed that satisfactory therapeutic results followed its administration in mich smaller and consequently less toxic amounts than had heretofore been prescribed. Why this observation, which depended entirely upon clinical acument, was not made mucb earlier is difficult to understand (3r).

The object of medical treatment in sneurymal dilatations is to initate nture's mode of cure by diminishing the blood pressure, retarding the velocity of the circulation, increasing the cosgulability of the blood, and provoking thrombos formation within the sac by agents which act directly upon the aneurymal tissues from within and without (46). These indications are best met by the dietetic, hygienic, and medicsl treatment which was introduced by Valsalva and Albertini inl728, Tuffnell and Billingham, and is still known by these names (cit. (46) 
They all aim at accorlishing the firet three indications in nearly the sare way. The originial Velsalve trestment consisted in absolute physical and mental rest, in rigourous diet, 125 erams of foo: per day, deprivation of fluids, and repeated bleeding, venesection, by which the volume of blood was reduced, the blood tension diminished, and the coagulability of the blood increased. The treatment was continued until the patient was too weak to lift his hand from the bed. (46)

Tuffnell (cit. (22)) about 1870 devised a variation of the Valsalva treatment which coneisted of placing the patient upon the minimun rich diet and forbiding even the slightest novement which can be svoided. The room must oe as quiet and secluded a fossible and no treatment by drugs to be attempted at the same time except those of constipation. Water intake limited as long as fulse and temperature are normal, or nearly so, and the whole allowence of solid food consumed. The durati:n of trestment must be two months absolute rest; then treatment relaxed only slightly for the succeeding six konths. It is important that a person of placid dispostion and sedentary habits be selected as it is useless to trest a laborer who has to seturn to hard work. Alcoholics vith degenerate vessels are also poor risks especially if they have syphilitic history. Where there is pressure on 
the esophagous or trachse, rest is not well bourne in a recumbent position and may result fatally 80 the aneurysm of ftysical signs, fror first part of arch of zorta, is more suitable for treatment than the aneurysm of the arch of the aorta.

Drugs are chiefly indicated to reduce the frequency of the heart beat and to diminish the arterial tengion. Nit rollycerin, tetranitrite, sodium nitrite, chloral, accnite, veratrum viride, etc, are all valuable when the pulse is rapid and the arterial tension is hith.

Crisp (12) in 1844 state that his treatment of aneurysms conaisted of repeated small bleedings, digitalis, and diacetate of lead. He states that the latter two are of little value: He recormends opium for the pain with which some patients are afflicted. A simple sparse diet and rest are equally important.

The one great advancement made in the treat rent of syphilis during the nineteenth century was the introduction of potassium dodide (35). Iodide of potassium appears to bave been the first used in treatment of tertiary syphilis by R. Williame (cit. (z5)) in 1831 and soon was ridely ueed; first by Nelaton in 1859 in and later by Borlland in 1862 on the claim that apart from syphilis it increased the coagulating fower of the blood. The rapid involuticn of the visiole lesions of late sychilis which followed its administrati $n$ gave it 
a prestige almost equal to that enjoyed by guaiacum in the early sixteenth century. For a while it arceared as if it would displace mercury in the treatment of syphilis. It was Fournier (16),1832-1914, who oa the wisdom of using merary and iodides in conjunction and the advantage of administering these two drugs intermittently over a lon period of time. De Haveland Hall (22) in 1913 stated that woh iodide of portassium had been given but as yet no cures had been reported. The treatment relleves symptoms for a time but they return and death is sure to follow. It relieves pain a great deal in most cases, but this, he states, so not altogether due to its antisyphilic froperties, but its more rysterious effects of lowering the blood pressure and tachycardis. Adequate dosage, 20 to 40 grams daily, is needed and, according to De Haveland Fall, the failure of the drug is dus to inadequate dosage as much as any other facoor.

of the numerous astringents and coagulants formerly preacribed, none renain except the names, The only remidies of this class that deserve mentioning are gelatin and calcium chlorid as their function was thought to be the coagulation of the blood (46). $T 1897$ M. Lancereau (41) of Paris fublished a new treatment of aneurysm. He injected 20 n grams of gelatine sui- 
cutaneously, repeated every three or four days. He clainto great relief from pain and diminution in the tumor $m \equiv 8 \%$. "The temperature may rise to 103 or 104 degrees and $01-$ though very alarmine no evil will result fror itn. Tris treatment was poorly received in England because of man $y$ cases of tetanus whish resulted from infroper sterilization of the gelatine.

Rankin (64) states that gelatine injections with froper precautions may be given subcutaneously with safety. He claims that in several cases injections of gelatine relieved all symptoms and in some the objective signs. His theory of the mechanism of the treatment is a shrinkage of the size of the sac with increased resistacne of the wall sac.

In 1900 Sir Oswal: Browne (10) at the society of Yedicine Londcn advocated calcium salts such 3 s calcium chloride and calcium lactate in hopes that they would favor coagulaticn of the blood. There is only one report giving this treatment a beneficial result.

The modern medical treatment of syphilitic aneurysm, as has been noted before, has been revolutionized by three factors: the discovery in 1905 by chaudin (69) that the spiorchetea fallidum was the etiological agent; the "rasermann fation test (78); and the laborous research of Erlich (12) in the discovery of Arsphenarine. 
The time to begin treatment of aortic ayphilis is during the primary stage or early secondary stage of syphilis $(z 0)$. In other words, if syphilis itself is treated early, the incidence of aortic syphilis is reduced to the vanishing point. If one waits until the signs or symptoms of syphilitic aortitis appear, such extensive damage has al ready been done that the physician cannot hope to do more than relieve symptoms, or at most, to retard the progress of the diaease.

When symptoms of syphilitic aortitis hav appeared, intensive antisyphilitic treatment should be instituted. The drugs which are universally employed are mercury, bismuth, potassium iodide, and one of the arsenical compounds $(20)$. Mercury, bi muth, and arsenic, have definite spirocheticidal action. The iodides possess no such power, but are useful in the latter stages of syphilis.

A course of treatment consists in the administration of mercury or bismuth for a period of twelve weeks, and six to eight doses of an arsenical compound, while pctassium iodide is being given. Two or three such courses are given in a year, with intervening rest periods of six weeks.

The signs of improvement under such treatment are: amelioration or complete disappearance of the symptom of sy hilitic aortitis, such as paroxysmal dyspnea, an- 
ginal pain, ani substernal discomfort; and improvement in the general condition of the patient. The appetite impooves, the weight increases, and the blood ficture becomes normal. The Tasermann reactior does not necessarily becone negative (20).

When cardiac decompensation occurs during the course of syphilitic eortitis, it should be managed frecisely like cardiac fallure under other circumstances.

The treatment of aneurysm, which is essentially that of syphilitic aortitis, should be carried out intensively. For the aneurymitself, in the early atages at leat, much be sccomplished by rest, rest in the recumbent posture, for as long periods as ten to twelve weeks. This diminishes the rate and force of the heart and consequently reduces the volume of the $8: 0$, which in turn relieves the subjective symrtoms. When the patient is finally allowed up and about, exercise must be restricted and physical strain reduced to 2 minimum.

The diet should be restricted to the quantity sufficient to maintain the nutrition of the individual. There is no advantage in restricting the fluid and food intake rigidly as in the Tuffnell foime.

Alcohol and tobacco are to be interdicted.

The various measures to increase the coagulability of the blood which have been suggested, such as frequent dmall bleedings, and the adminstration of calcium lacate, 
gelatin, etc. are of little value (20).

To relieve pain due to the erosion of bone, local applications of heat, in the form of flaxseed coultices, or an ice-cap applied directly over the seat of the disconfort may be helpful. For the more severe neuralgio pain, or the attacks of angina, morphine must be administered bypodermically, in quantities oufficient to bring relieve.

Paroxysmal dyspnea may in some instances be controlled by the administration of the nitrites. If the paroxysms afe repeated at frequent intervals, morphine or chloroform inhalations must be enployed (20). 


\section{TRFATM FNT-SURGICAL}

The surgical treatmient of aneurysm corsists of measurea applied airectly to the eneurysmal sac (46). These include compression, acupuncture, filipuncture, electropuncture. These methods are only semisurgical or quasmedical as long as they do rot include the ofen sections of the tisoues in order to axroach the aneurysm direct1y. The strictly speaking sur ical methods, apart frow the above, are tire classic operationo, the ligature, in its variau applicaticns, above and below the sac; the occlusion of the parent artery by constricting appliances; grceual ocolusion; Halsted's bands; gradual compresiion with graded clamss; elastic ligetures; the radical operations, as by incision of the sac, aneurysmectomy witr. ite $1 \leq \mathbf{r g e r}$ mocifications.

In the preantiseptic ferlod, when all operations involved seriolis risk, compression was regarded as the method of election in the treatment of aneurysu. The object of pressure is to bring about consolidation of the aneurysm by the formation of either a lamincted or an ordinary coagulum. The methods of bringing this about may be considered as direct pressure on the eneurysm, indirect or direct fressure either on the artery or the artery below or on both simulteneously. Compresion of the artery above the aneurysm, or 
indirect pressure, was first applied in 1784 by Desault (cit. (46)) who vas likewise the forerunner of John Hunter in the ligation of the artery above and at a distance from the sac. It was not frequently adopted, however, until 1844 , when it ws brought rore frominentIy to frofessicnal attenticn by several Dublin Surgeons, and by the greet suthority of Broca in France, who warmly advocated in in 1863. It is applied to the artery above, the artery below, or to both at the same time. In either case its object is to rromote the coagulation of the sec contents. Its mode of applicetion may be classified into digitel pressurep instrumental compression; elastic compression; and compression by flexion (46).

Direct fressure over an aneurysm and limites to its ourface is row never practised. Ffforts to control the Erowth of a thoracic or abdominal aneurysm by compression have proved digastrous, being followe by embolism or by rupture into the internal cevities of the body (46). The vsrious wethods of ligation of the artery froximal to the aneurysm depend on a decreased pressure and clottin witrin the sac for their curative effect, a result not always acrieved because of the development of collateral circulation (28). Historically, specific names hace become identified with certain ligations. Antyllus (cit. ( 28$)$ ) a Roman of the thiro century, A.D. is credited with having ligated the vesel proximal and 
distal to the aneuryswal sac, following which the sac was opened and evacliated. Anel of toulouse (cit. (aE)) in 1 rio described ligating the artery just frosimal to the sac, vihereas in $1786 \mathrm{Jchn}$ Hunter first employed his classical operation in Hunter's canal for a popliteal aneurysa. Anel's ligation is performed at a site likeIy to be involved in the pathologic process, wheress the Hunterian ligation is performed at a roint where the vess el wall is normal, thus reduoing the danger of erosion of the wall and secondary hemorrhage at the site of the ligation.

Brasdor (cit. (28)) a French surgeon, in 1760 advised ligating the artery dists 1 to the aneurysm. If there are no branches of the vessel between the aneurysm and the diatal ligation, this should be en excellent frocedure, inasmuch as Falsted (cit. 28)) has shown that there is very little pulsation in the part of the vessel lying between the ligature and the first branch froximal to the ligeture. This being true there should be little pulsation in the aneurysmal sac which lies froximal to the ligature. Distal ligation is applicable to aneuryms of the aorta and iliac, innominate, carctid, and subclavian arteries.

All ligaticns have an inherent defect; they do not attack the aneurysmal s c directiy (46). Extirpation 
of the sac has been repeatedly advocated, but the dangers ere real. Adjacent structures, such as rerves, may be so intinately bound to the sac that its excision would endanger the distal nerve suxkly. Moreover, such excision would endanger the collaterals rresent in the tissues surrounding the aneurysn. Both these defects are remedied by the excellent operation of Matas (44), first used by him in 1889 and since aplied uith remarkable success in many hundreds of cares. The operation depends on the feasiblity of completely controlling all circulation through the sac by the application of a tournicuet or by the application of arterial clamps to the vessel proxinal to the sac. In the case of a fugiform aneurysm the sac is boldly cpened, the clots removed, both arterial orifices and all branch openings are closed by indivicual transfision ligatures. The sac is then obliterated by successive rows of ligatures afflied to the sac. This utas (46): entitled the nobliterative endoaneurysmorrhaphy". The sacculated aneurysm is also boldly entered and occasionally the ofening from the artery itself can be sutered and its closure reinforced by suturing the walls of the ssc over it. This was called. restorative endoaneury smor rhachy. Then preservation of the main channel ould seer necessary for life of the limb, Matas (44) advocated the reconstructive endoaneu- 
ry anorrhaphy; the continuity of the parent artery may be restored by making a new channel. out of the sac walle, which can be brought together by suture ovir a guide (catheter or drainage tube) inserted into the froximal and distal openings of the aneurysm. Before tying the last suture the guide is removed and the channel is left behind, corresponding to the outline of the original artery. Fven trough such a passage nay ultimately close by clotting, the temporary as istance to circulation through this restored artery way be sufficient to prevent gangrene.

On June 25, 1817 Sir Agtley Cooper (cit. (75)) ligated the abdominal sorta for left illio femoral aneurysm in a man 38 years of age. Death took place in three days. Since that time there have bben about 20 attempts at lieation of the aorta (9). Some of these early intrepid experimenters are: Jones, 1829; Murray, 1834; and Monteiro, 1842; Some causes of death were shock, gangarene, ligation of ureter, ligature cutting through the vessel and hemorrhage, infection of the bowel, etc. (cit, (75). In 1899 W.W. Keen ligated the abdominal aorta just below the diaphragn for ruptured aortic aneurysm. Deat $h$ occured in 48 days from the ligature cutting through the acrt: with hemorrhage. On June 20,1904 A. Cuinard (cit. (75) ) Iigated the thoracio aorta about the level 
of the ninth thoracic vertebrae; death occurred in three days from suppresion of urine.

In April 1906 R. Lozano (cit. ( 75 )) ligated the abdominal aorta by the method of Matas endoaneuryamorpaphy. The patient lived eitht hours and died from shock and hemorrhage due to sutures cutting through the diseased walls of the vessel.

Geo. Tully Vaugh (75) in 1921 claims credit for one of the only successful ligations of the abdominal aorta for aneurysm. In 1919 he tied the abdorinal aorta just below the inferior mesenteric artery with a piece of tape. After cne year and four months the patient wes well and harry.! J. Shelton Horsley (abst. (9)) in 1926 said that this patient lived two years and one month after the operation. Post mortum showed that the aneurysm was not cured, but benefited.

Rudolph Matas (45) reported in 1925 that he ligated the abdominal aorta in a patient of 28 yeare just above bifurcation for bilateral iliac aneurysm. He used cotton tape suture. The patient died eeventeen months afterward of fulmunating tuberculosis and ruptare of branch of fulmonary artery. In the autorsy the aorta was fcund to be only partially occluded. Matas says that cotton or silk bands ot ay better, are less likely to cause premature ulceration, Etrophic or nectrotic 
changes in the artery wall which may end in disasterious hemorrhage. There ws no nectiotic or degenerating changes in the intina here but a dense capsule of fiberous tisgue of new formation which strengthened the vessel wal1. Fascia or other less available material would seem a superflous resort.

If the parent vessel of an aneuryscould be satisfact torizy occluded slowly enough to permit a concomitant developrent of atisfactory collaterals, a great step foreward in the treatment rould be taker. palstead (cit. (5)), 1905, devised a method. It consdsta in brief, in partially constricting the vessel by means of an instrument especially constructed for that purpose. The idea being that when the lumen had been perhaps not quite ocoluded complete obliteration might result syontaneousIy with the conversion of the arterial wall embraced by a band into a solid cylinder of living tissue. Tis may be considered the deal closure of an artery. According tc Enilie Holman (28), however, erosion of the arterial vall under the aluminum band is an ever present danger.

Halstead (23) in 1918 found there is frequently dilatation of the vessel on the distal side of the band which 1 a due to formation of eddy currents in the partially obstructed current. 
Less dangerous is a narrow strip from the fascia lata which way be emrloyed for partial oc lvion by wrapping it twice around the artery and suturing the ens together. Recanilization of the artery occurred, howeve", so the method was not too successul ( $(9)$.

Barney Brooks (9) an eminent authority on zortic ilgation, gives the froblems of ligation of this large vessel as bility to obstruct vessel vithout constricting material cutting through vessel, and a knowledge of an already existing collateral circulation or of a method of its production before complete obstruction. Brooks concluded that operation is foseible and compatable with life if collateral circulation is present. Absence of pulsation of femoral artery show that collateral circulation is present and indicates, operation is successful. The rresent method of obliteration is bad as silk suture will cut through and fascia is socn relexed and will not hold. we scys most fatients die because of heart strain in forcing blood through the collateral circulation, so surgical li gation is not 80 good. Matas operation is better in most cases, except in sortic aneurysm as sutures vill not hold in the diseased tissue.

Aseptic acpuncture (needling), practised by Mscewan (43) in 1890 for inoperable aneurysk, consists in the introduction of a long needle into the aneurysmal tumor, 
where it remains twenty four hours, during which the needle is moved sufficiently to scratch the intima and produce sufficient irritation to induce the formation of white or plate-leukocyte fibrin thrombi. The method is prectically abandoned on account of 1 ts uncertainty, the difficulty of limiting the effect of the punoture to the internal surfaces, and the fact that the aneurysm is already lined with laminated clot (46).

In 1864 Charles E. Moore (51) put the first retained wire into an aneury am. This treatment was widely used. In 1879 Corradi (cit. (30)) modified this treatment by passing a galvenic current trrough the wire. The MooreCorradi treatment has been used by Dr. Finney (oit. (30)) of Baltimore, and others, a great deal during the past few years. Briefly Finney's technique is as follows: pe uses a sizver and copper alloy fire wound on a spool to make it coil as it pasee through the aspirating needle. The needle is coated vith laquer to prevent burning the tissue with necrosis end hemorrhege. Under looal anaesthesia the needle is put into the sac and a 75 ailli amp galvanic current passed through the wire and the needle is withdrawn; the wire cut and left inside.

About 1903 Colt (62) devised a method by wilch a number of pleces of flexible wire could be introduced 
into the aneurysm through a cannula and when in the aneuryem orens up as an urbrella or wire cage and thus reinforces the aneurysm.

R. Sleigh Johnson (34) concluded that the causes of failure in wiring are the lengths of operation, the severity of hemorrhage, the lack of control over coils of wire which have sometines entered heart or main branches of the sorta and sepsis.

Rawley Penick, Sr. (6I) uses a spinel puncture needle and puts it into the aneurysm under the flaroscope. He then uses continuous wire loops which be watches go into the aneurysm by the fluroscope putting two feet at sa time in until about ten feet is ut in, checking with fluroscope after each two feet is rut into the aneurysm. The results are good with no decths. There is a disappearance of pain and pulsation ceases. The fatient resumes ris normal activity after a month or so of rest.

Blakenore and $\mathrm{King}(6)$ attempted a method in which the blood velocity, not the size of the aneurysm, indicates the amount of wire necessary to retard the amount of flow to the patient at which domplete mass cloting takes place. Fomer methods of wiring aneuryems gave no index of blood velocity $\equiv S$ a guide to the amount of vire necesary in a given case. Blood circulation under pressure creates a strain on the wall of the sac 
varying with the square root of its surface area and to Elesser extent with the rate of blood flow. Doubling the diameter of an aneuryem increases the strain on the sac 100\%. The stretched sac, further devitalized (as its nutrition and strength decends largely or an outgrowth of collateral vesaels about the neck), is of course weakened. In a clotted aneurysm, however, the physical laws governing solicis obtain. Thus the strain on the sac of an unclotted saccular aneurysm multiplies with growtr, whereas filling the sac conpletely with a solid clot reduces the strain on the sac to that of the lateral wall preseure on the surface area of the mouth of the sac ( 6$)$.

Inactivation of an aneurysib by clotting cannot be accomplished without bringing about two important conditions: presence of an adequate clot stimulating surface; and sufficient reduction of the velocity of blood flow. Heated mire introduced into an aneurysn decreases the blood flow and also offer an exc ellent clot stimulating surface of protein coagulation. Blakemore and $\mathrm{King}$ (6) selected an alloy of $90 \%$ siver and $10 \%$ copper in 34 gage which has the proper electrical resistance for heating. The siall size (one half the size formerly used in wiring aneurysm) and its lack of gring make it safe to use in adequate amounts. 
By a clever mechaniam which Blakemore and King call a "wire reel", they are able to pass about 33 feet of wire into an aneurysm. in four minutes oy bending the wire sharply in the center of the 33 feet length and pasoing it double through a special needle thus forming 10ops of wire inside the aneury awal sac. Since the operator knows the tencerature charges can be followed by brige reasurements. The current required to hest the wire to any desired level is dependent on two factors: the amount of wire and the rate of cooling, which is dependent on rate of blood flow. By calculat on a good Index of the velocity of blood flow is obtained. The amount of wire necessary for clotting of blood in the aac can be di redtly computed and the variety of aneurym can be deternined.

Adherence to the sac wall of a clot deposited within an aneury om is imperative and its orgenization desirable. Wire alone may reinforce the blood clot, but heating to 80 degrees wire on the inside surface of an aneurysm sac may $c$ euse inflammation of the sac wall.

Tissue subject to a temperture of 80 degrees for a fev moments reacts within 34 hours with dema, vascular engorgement, dilatation and a typical inflammatory reaction on the part of the white blood corrusles. The peak of the inflammation is reached in from two to six 
days. This is followed by a period of refain inwhich fibroblasts appear and tissue organization takes place with the aid of budiing carillaries. The entire reaction occupies frox ten to twelve days. For this resson they refest the wiring of the more active aneurym at twelve or fourteen day intervels. They say that this repetition has the added advantage of determing the progress of clotting.

Blakemore and King (6) conclude thet thoroughly clotted aneuryem may be inactivete; their method is safe and efficient; hesting to $8 n$ degrees within the sac wall promotes adherence and organization of the clot defosited. They have seven living examples of their work relieved of pain and symptoms.

W. T. Babcock (2) atates that ligation is harmful from the standpoint of hydrodynamics. And wiring, he ol aims is dongerous and uncertain. So he devised a method of decompressing sortic aneurysms by dividing the common carotid artery and the internal jugular vein in the neck, and $h$ ving ligated the distal ends, heve united the cardiac ends of the vein and artery. Thus, a by pass is provided permitting the jlood to pass from the high pressure arterial systeri to the low or hegative pressure of the descending vena ceva and a leakage is frovided from the aneuryom and adjacent gessel. Due to this lealage 
the blood casses more rapidly through the aneurysm, the wall preseure of which is reduced; the systolic blood pressure falls; the ane urysm becomes smaller; the auricles of the heart fill in a much shorter time and thus "the law of the heart" is reduced. The pulnonery arteries carry partially oxygenated blood and the reepirations are slowed. The strain on the arterial system is lessened and danger of enlargement and rurture is decreased.

There have been about 50 of these done by various ourgeons (1932) and Babcock claims relief from pain, and tncreased length of life. He claims there is no cerebral degeneration (at least in Logr).

As an alternative or if the first operation should not give a sufficient degree of decompression, Babcock(3) coneiders the possible use of the subolavian vein on the opposite side of the neck; or the subclavian artery and vein may be used. Babcock claims that a lateral or si de to side anastarroeis between artery and vein may do great harm. The effect is quite different from that of an end to end union, which is the only type to be considered a ther sutic measure.

Saleeby and McCarthy (66) reprot in 1938 that although the freaent treatment of internal aneury om is unsatisfaotory, they have found that the Babcock procedure offers the beat means of alleviating the symptoms of intra-thoracic and subclavian aneuryams untreated by other means. 
PROGNOSIS

The aver $y$ duration of life after the onset of symptom $\mathrm{may}$ be fron on to two years with aneuryam, but there 1s great variation (38). Associated hyserpiesis about double the changes of complicstion and mortality. Fard minual labor i- bad for prognosis in aneurysm.

About one half of aneurysts end in rupture. Treatment Doubles tre life expertance if dore correctly, but it is not clear how much the apparent effecta of treatment are due to the selection of patients (38).

Syphilitio sortic aneurys which do not involve the aortic valve srea may $b=$ fresent withcut hesrt fai ure whereas aneuryar: involving the aortic valve frequently reault in death from mocardial insufficjency (19).

In reference to juration of the symptors, Boyd (7) studied 830 unselected cases. 312 of them were under three monthe wich he says is undoubtely high because the ones which run $\equiv$ shict course are more likely tc be reported. Two types of sneurysme run a short course: those of the sinuses of alsalva mich rupture early, and early deaths due to undetected descending aneuryem. These statistics are mieading in that any aneurys, derending on the tyce, way last a variable lengtr of time.

Average durstion of time before diagnosis was rade 
is 36 month (49). The more renote from the reart the Ionger the tine before diagnosis.

Death in aneurysm maybe due to any of three causes: First those wilch die of some diseas: separete and distinct from aneurysm, which are not too common. secondly those who die from ruxture of the sac. This grour conetitutes abovt $52 \%$ of the deatho. Tiere is a high er eent se of rericarial ruptures. The left pleurg and esophagous rank next to gericardial ruptures. The third type is due to mechanical effects of the sao, such as heart failure, erosior of the spinal cord, and comrression of the axygos major causing fleural effusion and its com licating factors, Ohronic pneumonia, is a frequent cause of death (7).

Garvin and Siegal (19) report of a $r$ re condition, corpulmonale due to obstruction of the rulmonary artery by aortic sy hilitic aneury sm causing a burdening of the right side of the heart resulting in hypertrophy of the right ventricle, the so celled cor pulmonale. These are aneurysm of the ascending aorta which are involved. The cor pulmonale has its own type of exitua well described in many textbooks of medicine. 


\section{CONCLUCIONS}

Aortic aneury am is not rare.

The etiology concerns syphilitic infection and weakening of the rredial coats of the aorta flus a strain.

75 to $90 \%$ of aortic aneurysm is syphilitic.

The rresent treatment of aortic aneurysi per se is unsatisfactory but aneurysms can be revented by adequate treamtent of early ayctilis.

Early diagnoeis is difficult because of its confusion with heart pathology and in spite of the valuable adjunct of roentgenology.

Prognosis is poor. 


\section{BIBI:I OGRAPHY}

1. Aetius

Aetii Medici Graeci Contractae Medicinal tetroibli per J num Coraruim, Basileae, 1543 (D.) Cited by Holcomb

2. Babcock, W.W. New Methods of Treating Diseases of the Vascular System: Amer. Jour. Surg. 16: 401,1929

3. Babcock, W.T. Operative Decompression of Aortic. Surg. C1. No. Am.; 2; 1031, 1929

4. Baillie, M. Morb1d Anatomy of the Fuman Body. Phil., Hickman \& Hazard, Ed. 3, 1820

5. Bernheim, B.M. Surgery of the Vascular Syatem. Phil. \& London, J.B. Lippincott, Co., 1913

6. Blakemore, A.H.Electro-thermic Coagulation of Aortic and King, B.G. Aneury om. J.A.M.A.; 113; 821, 1938

7. Boyd, L.J. A Study of 4000 Reported Cases of Aneu-... fyom of the Thoracic Aorta. Am. Jour. Med. Soien.; 168: 654, 1924

8. Boyd, Wm. Pathology of Internal Diseases. Phil., Febiger \& Lea, 1936

9. Brooks, Barney Ligation of the Aorta. J.A.M.A., Section on Surgery, 116, 1926

10. Browne, Sir Oswald Discussion on Aneurysm at the Medloal Society of London. Trans. Med. Soc. London; XXIV: 52, 1901

11. Butler, C.S. The Antiquity of Syphilitic Aneurysm. The Military Surgeon; 82: 485, 1938

12. Crisp, Edwards A Treatise on the Structure, Disezses, and Injuries of the Blood Vessels with Statiotical Deductions. London, John Churchill, 1847

13. Ehrlich, P. The Experimental Chemo-therapy of Spiand Hata, S. Filloses, Translated by A. Newbold, London, Rebman, Ltd., 1911 Cited by Kemp 
14. Erichsen, J.E. Observations on Aneurysms Selected from the Works of the Principal Writers on that Disease. Printed for the Sydenham Society, London, 1844

15. Fernelius

De morbis universalibus, Lugduni Batavorum, VIII: 1645 From (14)

16. Fournier, A. Traite de la syphilis, periode tertiatie, Paris, F. Rueff, II: 1901 Cited by Kemp

17. Freedman, E. Development $\equiv 1$ and Life cycles of ThorHigley, C.S. acic Aortic Aneury ams. Am. J. of Roent. and Hauser, H. 39: 720, 1938

18. Galen, C. Opera Omina. Venet. ap. Juntas, 1609

Tom. 1., iil, et viii Frot (39)

19. Garvin, C.F. Cor Pulmonale Due to Obstruction of and Siegel, M.t.the Pulmonary Artery by Syctilitic Aortic Aneurysms. Am. Jour. Med. Scien.; 198: 679, 1939

20. Goodridge, M. Diseases of the Arteries. Textbook of Medicine. Cecil, R.L.. Phil. \& London, W.B. Saunders Co., 1937

21. Grahm, E.V. Aneurysm of Ductus Arteriosus. Arch. of Surg.; 41: 334, 1940

22. Hall, F.deH. The Lumleian Lectures on Intrathoracic Aneury $a m$. Reprinted from the Lancet, March 23, 29, and April 5, 1913, London

23. Halatead, W.S. Cylindrical Dilatation of Common Carotid Surg. Gyne. \& Obst.; 27: 547, 1918

24. Harvey, Wh. De Motu Cordia, English Translation by C.D. Pake, Springfield, Ill., Thomas, 1928

25. Hirschfelder, A.D. Diseases of the Heart and Aorta. Phil. \& London, J.B. Liprencott, Co., 1910

26. Holcomb, R.C. Aortic Aneurysm and the Antiquity of Syphilis. The Military Surgeon; 84: 199,1939 
27. Holcomb, R.C. Who Gave the World Syphilis? The Haitan Myth, New York, Froben Press, Inc., 1937

28. Holman, E. Aneurysms. A Textbook of Surgery. Christopher, F.. Phil. \& London, W.B. Saunders Co., 1937

29. Holland, L.F. Dissecting Aneuryss. and Bayley, R. Am. Heart Jour.; 18: 223, 1940

30. Horsely, J.S. Operative Surgery. and Bigger St. Louis, C.V. Mosby Co., 1937

31. Hunner, G.L. Aneurysm of Aorta, Treatment by Insertion of a Permanent Wire and Galvanisa (Moore, Corradi Method). John Hopkins Hoop. Bulletin; XI: 263, 1900

32. Hunter, J. A Treatise on the Venereal Diesease. Am. ed. 1; Phil., J. Teboter, 1818 Cited by Kemp

33. Hunter, Wm. Medical Observations and Enquiries, London, 1761 From (14)

34. Johnson, R.S. Aneury of Thoracic Aorta Treatment by iring with Colts Apparatus. Lancet; 1: 1037, 1940

35. Jump, H.D. Abdominal Aortic Aneurysm and Leaman, W.G.Internal Clinic; 1: 166, 1939

36. Kampmeier, R.H.Sacoular Aneurysm of the Thoracic Aorta: A Clinical Study of 633 Cases. Ann. Int. Med.; 12: 623, 1938

37. Kemp, J.E. An Outline of the History of Syphilis. Am. Jour. of Syphilis; 24: 759, 1940

38. Kilgore, E.S. Aneurysm. Tice Practice of Medicine; 4, 69,1940

39. Klotz, Oscar Concerning Aneurysm. The Third Gordon Bell Memorial. Toronta, Uni. Toronto Prese, 1926

40. Lamb Syphilitic Aneurysm. Nelson Loose Leaf and Turner, R. Medicine; IV: 337,1937 
41. Lancereaux, E. Du traitment des anevilomes en general et de l'aneurisme de l'aorte en particulier. Academie de Medicine, p. 784, 1897 Cited by Rolleaton

42. Lancisi, J.M. De an eurysmatibus. Romae, 1728 From (14)

43. Macewen, Sir Wr. On Aneurysm, its Cure by Inducing the Formation of White Thrombi in the Sac. Lancet; 2: 1086, 1890

44. Matas, R. Endo-aneurismorrhaphy. Surg. Gyne. \& Obst.; 30: 456, 1920

45. Matas, R. Ligation of the Abdominal Aorta. Ann. of Surg•; 81: 457, 1925

46. Matas, R. Diseases of the Vascular System. Keens' Surgery; 5: C. 70, 1909

47. Maurer, E. Absence of Pulse in the Vessels of the Upper Extremities and Neck in Aneury sm of the aortic Arch. Am. Heart Jour.; 17: 716, 1939

48. MoCrae, T. Dilatation of the Aorta. Am. Jour. Med. Sci.; 140: 469, 1910

49. Mills, J.H. Clinical Aspects of Aneurysm. and Horton, B.T.Arch. of Int. Med.; 62: 994, 1938

50. Honro, D. Essays and observatione,. Physical and Literary; 3, 1777 From (14)

51. Moore, C.H. Consolidation of Fibrin in Certain Incurable Aneurysms. Royal Med. \& Chirurgical Soc. Trans.; 1864

52. Moore, J.E. Treatment of Cardio Vascular Syphilis. Danglade, J.H. Arch. Int. Yed.; 49: 8\%9, 1932 and Reisinger, J.C.

53. Morgagni, G.B. Mayor, R.H.; Classic Descripti ns of Disease, Springfield, Ill., Thomas, 1932 Cited by Kampmeler 
54. Nichols, C.F. A Study of Syphilis of the Aorta and Aortic Valve Area. Ann. Int. Med.; 14: 1940

55. Nichols, C.F. Anneurysms of the Ascending Aorta, ArOstrum, H.T. tic Arch and Innominate Artery. and Tidmenn, B.P. Am. Jour. of Roent.; 43: 845, 1940

56. Oliver, N.S. Tracheal Tugging.

Lancet; 2: 406, 1878

57. Osler, Sir $\mathrm{Mm}$. Syphilius and Aneurysm.

British Med. Jour.; 2: 1510, 1909

58. Osler, Sir Aneurysm. System of Medicine. by Allbutt \&olleston; 6: 620, 1909

59. Paracelsus

In Proksch's der Antimercurialismus in der Syphilis-therapie, Erlangen, Ferdinand Enke, 1874 Cited by Kemp.

60. Pare, A. Deuvres Chirurgicales (1533). Lyon; 1641 From (14)

61. Penick, R.M. Technique for Wiring Aneurysms. Southern Med. Jour.; 31: 1096, 1938

62. Power, D. Aneury om of the Abdominal Aorta Treatand CcIt ed by Introduction of a Silver wire. Medico Chirargicel Trans. of London; 86: 363,1903

63. Pussey, W.A. The History and Epidemiology of Syphil1s. Springfield, IIl., C.O. Thomas; 1933

64. Rankin, G. - Treatment of Aneurysms by Subcutaneous Injection. Medico Chirargical Trans.; 86: 377,1903

65. Rolleston, H.D.The Harvelan Oration; delivered before the Royal College of Physicians, London. Cambridge, University Press, 1928

66. Salleeby, E.R. Aneury sms. Penn. Med. Jour.; 41: 969, and McCarthy 1928

67. Soarpa, A. Sull' Aneury gma. Pavia, 1804

Cited by Klotz 
68. Schamberg, J.F.Treatment of Syphilis, New York, D. and Mright, C.S.Appleton and Co., 1936 Cited by Remp

69. Schaudinn, F. Zur Kenntnis der Spirochaete pallida, neut sche med. Wohnschi; 31: 1665, 1905 Cited by Kemp

70. Shennan

Dissecting Aneurysms.

Med. Research Council, London, His Majesties Stationary Office, 1934

71. Shimkin, M.B. Aneury sm of the Aorta with Compreseion of the Spinal Cord. Ann. Int. Yed.; 12: 1709,1939

72. Singleton, H.0.Use of Intra-arterial Injection of Sodium Iodide in Determining Condition of Circulation of Extremities. Ann. Of SurE.; 16: 1232, 1938

73. Smith, L. Essential of Pathology and Gault, E. New York, \& London, D. Appleton-Century Co. inc.;

74. Van Swieten, G. In Proksch's die Geschichte der venerischen Krankheiten, Bonn. Peter Hanstein; 2: 426, 1895 Cited by Kemp

75. Vaughn, G.T. Ligation of Abdominal Aorta for Aneury am (Partial Occlusion). Ann. Surg.; 74: 308,1921

76. Villalobos In G. Gaskoin's The Medicgl Works of Trancisco Lopex de Villalobos, London, J. Churchifl \& Sons, 1870 Cited by Kemp

77. Von Glahn, W.C.Syphilitic Aneurysm.

Neslons Loose Leaf Med.; 4: $337 ; 1937$

78. Wassermann, A. Eine serodiagnosticche Reaktion bet Neisser, A. and Bruck, C. 32: 745, 1906

79. Welch, F.J.' Aortic Aneury am in the Army. Lancet; 3: 769, 1875 Cited by Kampmeier

80. Wilkg, Sir S. Syphilitic Affections of Internal Organs Guys Hosp. Reports; 9, 1863 
81. Wang, Chi-min

History of Chinese Medicine Tientain, China, The Tientsin

Press, Ltd., 1932 